\title{
Colombian National Cancer Institute
}

The National Cancer Institute of Colombia was created to serve scientific progress and the Colombian people. The idea of an institution that would focus on cancer patients was conceived by Prof. Claude Regaud at a conference on November 15, 1928 about 'How to Organize the Struggle against Cancer'. Enthusiastic with this presentation, the then Minister of Public Instruction, Dr. Jose Vicente Huertas had a law approved by the Congress which allocated $\$ 40,000$ for the creation of the National Radium Institute as part of the National University. Dr. Huertas then requested Prof. Regaud to do a detailed study on the creation of the Institute. This report was published in Paris in June 1929. Other governmental and private funds were provided during the following years. The construction and equipping of the Institute were completed in July 1934. The reputation of the Institute began to expand rapidly, being the only hospital of this type in Latin America.

The second director was Dr. Augusto Pantoja who took office in 1945. At the end of 1946, the scientific progress achieved by the Institute showed itself by the publication of a work on cancerology and radiotherapy written by 17 members of its staff and widely distributed. On January 1, 1951, the Radium Institute became part of the Ministry of Health. Dr. Jose Antonio Jacome was appointed director. On February 27, 1953, the name of the Radium Institute was changed in to 'National Cancer Institute'. During the same year, a Radioisotope Laboratory was created. The first application of radioactive material, other than radium to cancer patients had already been done in Colombia in 1950. Dr. Jaime Cortazar became director in 1955; the scientific training program of the Institute was enlarged under his guidance and stress was laid on nuclear medi-

cine. In November 1957, Dr. Mario Gaitan Yanguas became director, and held this position during the following 17 years. On July 6, 1960, the Institute became a decentralized entity with its own board of directors. During the same year, a National Committee against Cancer was created whose purpose was to organize and carry out national campaigns against cancer throughout the entire country. Meanwhile, the Institute continued to develop both its structure and its national significance. It already comprised several medical sections besides those of radiotherapy, surgery and internal medicine. Postgraduate education was developed in other areas as well, including social work and odontology, while emphasizing basic training in cancerology. The Institute celebrated its 30th anniversary in 1964. During the preceding 10 years it had assisted 40,000 new patients and completed 75,600 clinical records. Its scientific and teaching activities were organized through research and training with the participation of the various division heads of the institution. The School of Cytology, inaugurated in 1968, focused on the training of technicians for the performance of the cytological diagnosis of cervical carcinoma. New equipment was purchased in 1969 for the Radioisotope Section which became the Section of Nuclear Medicine in 1971. The Experimental Biology Laboratory was started; it was equipped with the first electronic microscopic unit in Colombia. In 1972, a chemotherapy group was created. A special edition of its bulletin, issued in 1974 on its 40th anniversary, reported on the activities of the preceding years. In the same year, Dr. Julio Enrique Ospina, a 
pathologist specialized in cell biology and electronic microscopy, succeeded Dr. Mario Caitan Yanguas. The new institute building was completed in 1978. The Institute launched a National Cancer Control Program after it was approved in March 1976. This program en127

compasses the decentralization of the services to cancer patients, through the creation of eight sectional branches located in different larger cities of the country, with university hospitals and well-structured health services. These sectional branches have been created and equipped with nuclear medicine and radiotherapy equipment, besides those already existing for the practice of surgery and other medical specialities. On the basis of this program, a National Chemotherapy Bank was created which operates within the National Cancer Institute and whose purpose is to maintain an adequate stock of cytostatic agents for the efficient treatment of patients. The National Cancer Control Program has strictly fulfilled the functions for which the Institute was created and has equipped it with the staff and facilities required for its cancer research, diagnosis and treatment services. It has also supported to a great extent the Institute's task, providing for the necessary equipment to produce teaching films not only for the students and physicians of the Institute, but also for those of the rest of the country. The publication program has been strengthened with the continuation of the Institute's bulletin and the creation of a journal which will periodically report the achievements of the Institute's staff. The scientific programs have been aided by new equipment handled by highly qualified personnel and the care of cancer patients has been significantly improved thanks to national development and cooperative surveys with several internationally known organizations such as the Roswell Park Memorial Institute of the United States. The School of Cytotechnology has maintained its teaching functions at the highest level. The School of Radiotherapy Technicians was founded and training is also being offered for specialists in internal medicine, surgery, pathology, radiotherapy, nuclear medicine and experimental biology.

Through the National Cancer Control Program, the National Cancer Institute serves the entire country. It accomplishes its mission of prevention, education, research, diagnosis and treatment. The Institute's graduates are trained for careers in oncology in an atmosphere of knowledge and service, and serve with enthusiasm, the cancer patients in Colombia. 